\title{
O absurdo no limiar do cotidiano: Melhores contos de J. J. Veiga
}

\section{Priscila Finger do Prado*}

\begin{abstract}
Resumo: No ano em que ocorre o $10^{\circ}$ aniversário da morte de José J. Veiga, bem como o cinqüentenário da estréia do ficcionista, buscamos desvendar a estranha realidade apresentada pelo autor nos contos selecionados por José Aderaldo Castello para compor Melhores contos de J. J. Veiga. Nossa proposta de análise dos contos abarca a relação entre o efeito de realidade capaz de ser ofertado pela literatura, e também a idéia de que a intensificação desse efeito pode constituir, na literatura, um resultado contrário, ou seja, de estranhamento. E são esses limites que buscamos analisar na obra indicada de J. J. Veiga.
\end{abstract}

\begin{abstract}
In the year that the dead of J. J. Veiga completes 10 years and the debut of the author completes 50 years, we find to analyze the strange reality presents at the selected short tales by J.. J. Veiga, chosen by José Aderaldo Castello to compose the book Melhores contos de J. J. Veiga. Our analyze's proposition privileges the relationship between the reality's effect and its contrary effect, the strangeness. So, these limits are searches to our analyze.
\end{abstract}

Keywords: J.J. Veiga, shot tales, reality, absurd.

Com esses e outros bichos, e mais outras coisas que aconteciam, a vida no rancho era cheia de sustos

(J. J. Veiga)

\section{Considerações iniciais}

Apesar de o realismo, enquanto convenção literária (WATT, 1999), ter dominado boa parte da literatura ocidental, o elemento insólito também se destacou, adquirindo diversas formas, de acordo com a época em que surgiu. Desse modo, tem-se elementos fantásticos desde as epopéias atribuídas a Homero até a literatura contemporânea.

Nesse cenário é que os contos de José J. Veiga se encontram, delatando o absurdo que as práticas cotidianas podem apresentar, sem que os sujeitos que as integram percebam-nas ou compreendam-nas. Dessa maneira, busca-se verificar como se dá a construção do insólito nos contos presentes na obra escolhida, cuja seleção é de José Aderaldo Castello, destacando a análise de dois contos em particular, que dão nome aos títulos das obras das quais os textos

\footnotetext{
* Graduada em Letras pela Universidade Federal de Santa Maria, Especialista pelo Centro Universitário Franciscano e mestranda pela Universidade Federal de Santa Maria (UFSM).
} 
foram extraídos. Melhores contos de J. J. Veiga consta, pois, de vinte contos, sendo nove deles oriundos do livro Os cavalinhos de Platiplanto (1974), e os onze restantes advindos de A máquina extraviada (1974). Conforme o exposto pelo organizador da antologia de José J. Veiga, em nota de rodapé, seis contos foram excluídos do total apresentado pelas duas obras, a fim de que se alcançasse o objetivo da reunião/seleção de contos.

O autor dos contos escolhidos, J. J. Veiga, é natural de Corumbá, Goiás, tendo nascido em 1915, e estreado na carreira literária tardiamente, em 1959, com então quarenta e quatro anos. Veiga teve produção intensa e contínua, sendo que dois anos antes de sua morte publicou dois novos títulos, Tajá e sua gente (1997) e Objetos turbulentos (1997).

A crítica literária geralmente aponta como características de sua obra, tanto contos como romances, a voz pueril que observa, vivencia e narra as ficções, bem como o espaço rural em que seus trabalhos se inserem. Outra peculiaridade da obra veiguiana, perante a crítica, é a presença de elementos fantásticos, próprios de um realismo maravilhoso que se desenvolveu na América Latina no início do século XX.

Nesse contexto, Selma Calasans Rodrigues busca apresentar os autores brasileiros que desenvolveram narrativas nas quais o insólito se faz presente, embora considere mais tímida a presença desse elemento no Brasil do que na América Hispânica. Para a autora, elementos fantásticos integraram obras de Machado de Assis; Mario de Andrade; Guimarães Rosa; Moacyr Scliar; Lígia Fagundes Telles; Flávio Moreira da Costa, entre outros. Contudo, os autores que contemporaneamente desenvolveram essa linha narrativa - e de forma mais similar à ficção hispano-americana - foram Murilo Rubião e José J. Veiga.

Estes escritores, embora aproximados pela presença do insólito em suas obras, diferenciam-se quanto à forma da aparição do maravilhoso no real construído em suas narrativas. Em Rubião, a apresentação do elemento insólito é mais dissonante da realidade proposta pelo texto, aproximando-se da linha surrealista, como no conto "O homem do boné cinzento", no qual o protagonista, um forasteiro, definha dia a dia, até que lhe reste apenas a cabeça com o boné cinzento. Também se percebe na ficção rubiana a ausência de demarcação espaço-temporal, o que a aproxima de uma constituição fabular. Já a narrativa de J. J. Veiga considera as possibilidades de o real parecer estranho, principalmente pelo tipo de olhar que é emitido para a realidade. Assim, a perspectiva do protagonista geralmente destoa das demais personagens, porque lhe cabe um olhar atento à realidade, passível de perceber suas estranhezas, ao passo que as demais personagens, geralmente integrantes do universo do senso comum adulto, vêem o cotidiano sem prestar atenção aos seus mistérios, sem indagar- 
lhes o porquê de assim serem, ou seja, com olhos acostumados, acomodados a ver o mesmo sempre da mesma forma.

Tal como o enunciado proposto com a epígrafe do presente artigo, o mundo ficcional dos contos escolhidos de José J. Veiga abarca os "sustos" que o cotidiano pode proporcionar àquele sujeito que ainda se impressiona com as sutilezas do dia-a-dia.

O cotidiano apresentado em Melhores contos de J. J. Veiga é o de propriedades rurais ou de pequenos vilarejos do sertão brasileiro, principalmente. Nesse cenário, em meio às regularidades do cotidiano, são inseridas ou descobertas situações que alteram a rotina, mas que não são vistas em sua absurdidade, pelo contrário, são aceitas com facilidade pelas personagens adultas, como resultado de uma acomodação e de uma alienação perante as circunstâncias e suas causas. A personagem que interpela e reflete os acontecimentos obscuros geralmente faz parte do universo infanto-juvenil, aplicando-lhe explicações de acordo com a sua visão do mundo.

O mundo infantil é contraposto ao adulto em vários contos, de forma a caracterizar o primeiro como fantasista, perante os olhos do segundo. Porém, fantasista ou não, ao mundo visto pelo olhar pueril nada escapa, a realidade não é dada, ela se constrói a partir das vivências e das impressões do ser em fase de desenvolvimento.

Para Massaud Moisés, a marca registrada da ficção do autor goiano é o realismo mágico, de forma que o trabalho de Veiga pode ser comparado ao de pintores surrealistas, como Magritte ou Delvaux ${ }^{1}$, no qual "a cinzentice da realidade cotidiana é atravessada por um objeto inusitado, criando-se uma atmosfera de magia" (2004, p.590).

A presença de um "objeto inusitado", que pode inclusive ser uma pessoa, no dia-a-dia de uma pequena comunidade, costuma causar estranhamento. Isso porque o cotidiano é o visto, vivenciado todos os dias, à maneira de hábito, seguindo uma rotina de acontecimentos ditos normais, isto é, que se desenvolvem dentro da norma. Dessa forma, estranho é tudo aquilo que foge a essa norma, que a subverte de alguma maneira.

Ao tratar o conceito de estranho, Freud (1976) lança mão da etimologia da palavra em alemão, descobrindo nela dois significados opostos que convivem conjuntamente: o de familiar e o de oculto. Para o psicanalista, tem-se um efeito de estranho, quando a distinção entre imaginação e realidade é extinta, ou seja, "quando algo que até então considerávamos imaginário surge diante de nós na realidade, ou quando um símbolo assume as plenas funções da coisa que simboliza, e assim_por diante" (1976, p.304).

\footnotetext{
${ }^{1}$ Exemplos de obras em anexo.
} 
Já na perspectiva da Teoria da Literatura, propriamente dita, Tzvetan Todorov (1975, p.31) aponta que a pesquisa do elemento causador de estranheza numa narrativa pode conduzi-la a três formas principais: o estranho, o fantástico e o maravilhoso. A diferenciação entre essas se daria pela relação entre o real e o ficcional, de modo que, quando permanecem as leis empíricas, o insólito pode ou ser explicado - e nesse caso temos a categoria do estranho -, ou permanecer sem esclarecimento, conservando-se certa hesitação - nesse caso, temos o fantástico propriamente dito. No caso de alterarem-se as leis que condicionam a narrativa, ou seja, quando se abandona a base empírica, temos a categoria do maravilhoso, na qual não há necessidade de explicação, pois o universo proposto não parte da realidade, e sim forja outro mundo em que os absurdos sejam possíveis e até normais, como nos contos de fadas, em que é possível a um sapo tornar-se príncipe pelo efeito de um beijo.

Contudo, na narrativa de J. J. Veiga, não se percebe a presença de uma dessas categorias. Existe um estranhamento, na concepção freudiana, mas este não se adéqua à divisão todoroviana. Conforme as palavras de Moisés (2004), citadas anteriormente, há na ficção de Veiga um viés que proporciona coexistência de elementos ditos reais e componentes maravilhosos. De modo mais específico, essa ficção busca o maravilhoso em meio à realidade, principalmente pelo foco narrativo, que empresta olhos para os mistérios das coisas simples e cotidianas.

Segundo Irlemar Chiampi (1980, p.52-72), ao caracterizar o realismo maravilhoso hispano-americano, duas são as peculiaridades pragmáticas principais dessa categoria narrativa: [1] o efeito de encantamento do discurso pela incorporação do insólito ao real e pela descontinuidade entre causa e efeito, em contraposição à poética da incerteza do fantástico; e [2] a problematização da enunciação, tanto ao nível da perspectiva, quanto ao da própria crítica do ato de contar.

Nesse sentido, a obra de J. J. Veiga se aproxima da categoria do realismo maravilhoso, já que, embora não problematize o ato de contar propriamente, oferece diferencial na questão da perspectiva enunciativa, de modo a caracterizar o maravilhoso pelo foco que se lança ao cotidiano. Assim, há na ficção veiguiana a incorporação do insólito ao real, exatamente pela perspectiva enunciativa, sendo que as relações entre causa e consequiência nos contos geralmente não são lógicas, no sentido tradicional, o que produz o efeito de encantamento no leitor, ao qual se referia Chiampi (1980).

Contudo, embora se aproxime da categoria proposta por Chiampi (1980), o insólito, na obra de J. J. Veiga, envolve principalmente o tipo de olhar que é lançado à realidade. Dessa forma, o absurdo pode estar calcado tanto na banalização de um ato/objeto convencional, 
quanto pela posição de questionamento de um sujeito perante um dado que é aceito pelo senso comum de determinada sociedade. Assim, os limites entre real e absurdo passam a depender do ponto de vista do protagonista e/ou narrador do conto, o qual pode aceitar o absurdo como norma (“A máquina extraviada”), ou perceber o absurdo na norma, naquilo que é aceito por todos ("Os noivos").

Para melhor observar essa tênue relação entre o real e o absurdo, nos contos de Veiga, parte-se para a descrição dos temas encontrados na obra, bem como para a posterior análise de dois contos, para que se possa explicitar como se constitui o insólito na narrativa veiguiana.

\section{Panorama dos contos}

Percebe-se dentre os contos de J. J. Veiga a persistência de alguns eixos semânticos, de forma que se optou por uma divisão temática, para possibilitar uma visão geral da obra em análise, Melhores contos de J. J. Veiga (2000). Destaca-se o eixo temático da confrontação entre a idade adulta e a infantil [1]; o da divisão entre aceitação da norma e sua refutação [2]; o da relação entre morte e amadurecimento [3]; e o da opressão do homem pelo progresso [4].

No primeiro eixo temático, "confrontação entre a idade adulta e a infantil", tem-se os seguintes contos: "Fronteira", "Os cavalinhos de Platiplanto" e "Tia Zi rezando", oriundo de Os cavalinhos de Platiplanto (1974); bem como "Diálogo de relativa grandeza", "O largo do mestrevinte" e "Na estrada do amanhece", provenientes da obra A máquina extraviada (1974). Nesta linha, destaca-se a relação de conflito entre as perspectivas infantil e adulta ao vislumbrar o mundo, de modo que se a criança percebe as surpresas que o cotidiano proporciona, o adulto as generaliza e banaliza, para mantê-las dentro do habitual. Na maioria dos casos, vê-se que, na perspectiva do narrador, a percepção adulta do mundo é até mesmo desvalorizada, como podemos notar pelas palavras do narrador de "Fronteira": "Eu era ainda muito criança, mas sabia uma infinidade de coisas que os adultos ignoravam" (2000, p.35).

O segundo grupo, "entre a aceitação da norma e a sua refutação", conta com quatro contos, dois pertencentes a Os cavalinhos de Platiplanto (1974): "Professor Pulquério" e "A espingarda do rei da Síria"; e dois advindos de A máquina extraviada (1974): "Os noivos" e "Os cascamorros". Verifica-se nesta temática a relação entre os adultos que aceitam as normas da sociedade sem questionar e os adultos que resolvem desafiar os preceitos vigentes, sendo marginalizados com os estereótipos de loucos ou de ingênuos. No conto "Professor Pulquério", o protagonista propõe aos moradores da vila uma caça ao tesouro, mas recebe por isso descrença e deboche por parte dos habitantes do lugar, tanto autoridades como cidadãos 
em geral. Com o que, nota-se que uma atitude ingênua é perdoada quando vinda de uma criança, que ainda não adquiriu por completo os códigos societais, mas não o é quando vinda de um adulto. $\mathrm{O}$ absurdo aqui vem da possibilidade de um adulto não se adaptar ao que se espera dele. A banalização e a generalização, portanto, cumprem papel importante para a formação do absurdo nesses contos. Já no conto "Os noivos", percebe-se que a radicalização do hábito também constitui absurdo. Aqui há uma separação entre o mundo dos noivos, presos à convenção do casamento, mas ainda não totalmente dentro dela, e o mundo natural, onde coexistem o vento, as estrelas e os ruídos da noite: "é possível até que os noivos sonhem, mas isso ainda não foi comprovado" (2000, p.112).

O terceiro eixo temático, "relação entre morte e amadurecimento", abrange sete contos da obra, sendo três do livro Os cavalinhos de Platiplanto (1974): “A invernada do sossego", "Roupa no coradouro" e "Entre irmãos"; e quatro do livro A máquina extraviada (1974): "A viagem de dez léguas", "Onde andam os didangos?”, “O cachorro canibal” e "Tarde de sábado, manhã de domingo". Nesta divisão, a morte aparece como a finalizadora de uma fase da vida que propicia a iniciação de outra. Pela noção de finitude dos seres e das coisas, as personagens adquirem visão mais ampla sobre suas próprias vidas, modificando alguns valores que lhes eram caros. No conto "A invernada do sossego", o narrador presencia a morte de seu cavalo, sendo que a solução encontrada para enfrentar essa perda é a crença em uma invernada "do outro lado do morro", para onde vão os animais desaparecidos. Contudo, com a perda do cavalo também morre o menino, nem que seja para que pudesse se transformar em um homem. Dessa forma, a morte física propicia a morte simbólica, que abre uma nova fase ao protagonista. Já no conto "Tarde de sábado, manhã de domingo", tem-se as travessuras de quatro meninos, que levam o quarto amigo à morte. Assim, mais do que a necessidade de ação dos três companheiros perante a situação derradeira, destaca-se o contato com a morte, o trauma que produz amadurecimento.

O último grupo temático, "opressão do homem pelo progresso", constitui-se de três contos, um advindo de Os cavalinhos de Platiplanto (1974), “A usina atrás do morro", e dois de A máquina extraviada (1974), "A máquina extraviada" e "O galo impertinente". Neste eixo, percebe-se a perda de função de alguns artifícios do progresso tecnológico pela naturalização de seu uso, pela banalização de sua aceitação pela sociedade. O progresso também surge como um inimigo "indefinido" do indivíduo que a ele não se adéqua ou que não coaduna com seus princípios, de modo que não há uma entidade à qual o indivíduo possa recorrer para reclamar a perseguição e a opressão sofridas pelo avanço da tecnologia. Sem rosto, o inimigo não proporciona ao sujeito discordante a possibilidade de luta, somente 
cabendo-lhe a acomodação às normas ou a sua exclusão/marginalização delas. O nonsense, neste caso, advém do desconhecimento que as personagens têm da engrenagem social a que estão inseridas. No conto "A usina atrás do morro", por exemplo, tem-se a chegada de forasteiros com o propósito de instalar uma fábrica no lugarejo. No entanto, a iminente instalação acaba por tirar a tranqüilidade da população, trazendo a invasão de funcionários em motocicletas vermelhas e a proliferação de espiões pela cidade. A narrativa é feita em primeira pessoa e o protagonista é quem prevê o estrago que os estrangeiros trariam ao povo. A linguagem neste conto é digna de nota, já que os forasteiros falavam uma língua que ninguém entendia, e a sua chegada ameaçou de tal forma àqueles que resistiam em aderir aos seus interesses, que as pessoas evitavam falar em público e só conversavam em casa aos cochichos. Ao protagonista, receoso de aderir à nova estrutura, restou-lhe fugir sem nada levar de seu, embora não tenha escapado de perder o pai com a ação "desatenta" (ou repressiva?) de um dos motociclistas. Segundo Malcolm Silverman (1978, p.160), o cenário desse conto se assemelha à ficção de George Orwel, dada a situação de apatia do povo perante os desmandos dos governantes ou detentores do poder, e também dada a repressão àqueles que se insubordinam. Já em "O galo impertinente", o elemento insólito é propriamente a existência de "um galo enorme" que não permite a passagem das pessoas por uma estrada recém-construída, que levara anos para a sua consecução. Com o fim da estrada, persiste o distanciamento do povo perante a obra, devido aos feitos do grandioso "galo impertinente" que tranca passagem. A presença do insólito aqui parece colaborar para a sensação de inutilidade da obra, com a permanência do modo de vida antigo da população, à parte da inovadora obra de engenharia. $\mathrm{O}$ conflito entre necessidade e função extrapola quando, ao final do conto, o narrador lança a possibilidade de uma nova geração de homens, quem sabe, conseguir compreender a existência do galo, bem como utilizar a estrada, agora coberta de mato e sujeira.

Por isso, vale reiterar, sobre o insólito nos contos de J. J. Veiga, que o que lhes confere estranhamento está ligado ao olhar lançado à realidade, seja de credulidade ou de niilismo cego, tanto um radicalismo quanto outro evoca o estranho para dentro da narrativa. A fim de melhor demonstrar como se dá a constituição do insólito nos contos, passa-se para uma análise mais detida de dois contos, que dão nome às obras das quais foram selecionados as narrativas de Melhores contos de J. J. Veiga (2000): “Os cavalinhos de Platiplanto" e "A máquina extraviada”.

\section{3 “Os cavalinhos de Platiplanto" e "A máquina extraviada": análise preliminar}




\section{1 "Os cavalinhos de Platiplanto"}

Os contos escolhidos para serem analisados mais detidamente pertencem a diferentes eixos temáticos, conforme anterior divisão, sendo que "Os cavalinhos de Platiplanto" se encontra no grupo denominado "confrontação entre a idade adulta e a infantil", e "A máquina extraviada", no eixo "opressão do homem pelo progresso".

Em "Os cavalinhos de Platiplanto", tem-se uma narrativa em primeira pessoa, na qual o narrador rememora acontecimentos de sua infância, especificamente o episódio em que pode conhecer os "cavalinhos de Platiplanto": "O meu primeiro contato com essas criaturinhas deu-se quando eu era muito criança" (2000, p.27). O advérbio de intensidade aqui sugere que mesmo tendo se passado algum tempo entre o momento do enunciado e o da enunciação, o narrador conserva traços infantis na sua personalidade, de modo que, agora, só é menos criança do que antes, razão pela qual ainda pode "ter contato" com as criaturinhas mágicas que posteriormente descreve no conto.

$\mathrm{Na}$ seqüência, o narrador descreve um episódio em que participa seu avô. Nesta ocasião, o protagonista ainda menino havia machucado o pé e tentavam-lhe convencer a permitir que o lancetassem, sem resultado. A chegada do avô na casa e a maneira deste lhe falar, "sem ralhar e sem tirar a razão da gente" (2000, p.28), faz com que o menino aceite o procedimento, mas com a promessa de ganhar um cavalinho da fazenda do Chove-Chuva, pertencente ao avô. Logo depois, o menino sara do ferimento, mas o avô adoece, e o menino entende o que vai suceder: "o meu cavalinho, nunca mais" (2000, p.30).

Contudo, a intensidade do desejo de ter para si o dito cavalinho, para o qual já escolhera até nome - Zibisco -, e a forte imaginação, típica de sua faixa etária, permitem-lhe uma visita à fazenda do Major, em um lugar chamado Platiplanto, onde pode observar todos os cavalinhos que o avô lhe destinara: "cavalinhos de todas as cores, pouco maiores do que um bezerro pequeno" (2000, p. 33).

Neste ponto da narrativa, observa-se, por alguns indícios lingüísticos, expressões de indeterminação espaço-temporal, bem como indicativos de incerteza do próprio protagonista que narra o que vivencia em Platiplanto, mas sem certezas racionais sobre o ocorrido: "Não sei se foi nesse dia mesmo, ou poucos dias depois, eu fui numa fazenda nova e muito imponente, de um senhor que tratavam de major" (2000, p.30). O caminho que percorre até chegar à fazenda parece coincidir com o amadurecimento que lhe é exigido para lidar com a ausência do avô, único familiar que não o tratava com diferença por ser ainda criança. É 
preciso atravessar uma ponte, ir para o "outro lado", conviver com perdas e acontecimentos negativos: "quando desci pelo outro lado e olhei a ponte enorme e firme, resistindo ao vento e à chuva, senti uma alegria que até me arrepiou [...] Olhei a ponte mais uma vez e segui o meu caminho, sentindo-me capaz de fazer tudo o que eu bem quisesse” (2000, p.31). Até chegar ao lugar onde estavam os cavalinhos, lugar de desejo, sonho e lembranças do avô, o menino encontra-se com uma espécie de seu alter-ego, "o menino que tinha medo de tocar bandolim" (2000, p.31), que lhe acompanha até o "outro lado do morro". No caminho, um perdeu o medo de tocar bandolim e o outro, de atravessar o morro. O rosto inimigo, necessário para que a história se efetivasse com seus desafios, percalços e júbilos, é encarnado pelo tio Torim, para o qual o menino aponta a razão de não poder ter o cavalinho prometido, já que o tio é que ficara na fazenda do avô: "Então não sabe que os homens de Nestor Gurgel [tio Torim] estão com ordem de pegar você vivo ou morto?” (2000, p.32), diz o dito major ao narrador-menino. Ao convencer-se da existência dos cavalinhos e da impossibilidade de levá-los consigo: "Eles só existem aqui em Platiplanto", o desejo do menino parece ter sido aplacado, nem que essa realização tenha sido somente em sonho, conforme divaga o narrador: "Devo ter caído no sono em algum lugar e não vi quando me levaram para casa" (2000, p.34). A realização do desejo de menino lhe é concedida, embora a personagem saiba que a compreensão do fato não poder ser alcançada pelos outros, por ser única e intransferível, e também porque os adultos com que convivia já haviam perdido parte da capacidade de imaginação e sonho que tiveram enquanto crianças: "Pensei muito se devia contar aos outros, e acabei achando que não. Podiam não acreditar, e ainda rir de mim; e eu queria guardar aquele lugar perfeitinho como vi, para poder voltar lá quando quisesse, nem que fosse em pensamento” (2000, p.34).

O insólito está ligado à relação entre o eu que vivencia e os outros que não o fazem, de modo que se pode entender que as experiências, os sonhos e os desejos de um indivíduo só recebem plena dimensão por aquele que os prova. O estranhamento se dá numa perspectiva freudiana, na qual algo considerado imaginário surge na realidade, de modo que de tanto idealizar o cavalinho, este lhe surgiu acompanhado de outros, com dimensões ainda mais mágicas que as antes imaginadas. O real obtém uma dimensão amplificada aqui, de modo que tudo aquilo que faz parte da vida de um indivíduo é real para ele, mesmo que não o seja para os outros. Contudo, se o indivíduo consegue dar provas de seu intento, passa não só a ser creditado pelos outros, pela sociedade, como também a ser enobrecido pelo feito, como ocorre no conto "A espingarda do rei da Síria”, no qual o narrador, após ser desacreditado pela comunidade vizinha, é enobrecido por suas relações com o dito rei da Síria, de existência duvidosa até se certificarem de sua presença. Nessa mesma perspectiva, em "Professor 
Pulquério", se este conseguisse comprovar a existência de seu tesouro perdido aos habitantes do vilarejo, seu status de louco e ingênuo passaria ao de gênio, perante a sociedade.

Os cavalinhos de Platiplanto causam estranhamento a todos aqueles não viram a graça com que saltitavam ou tomavam banho. O absurdo aqui, então, é entender a experiência do outro, quando esta não produz resultados concretos.

\section{2 "A máquina extraviada"}

Em "A máquina extraviada", há o conflito entre importância e funcionalidade de um objeto, sendo que o aparecimento de uma máquina em um lugarejo é aproveitado ao modo dos habitantes do local, que desconhecem a verdadeira função da máquina. A narrativa é feita nos moldes da oralidade de um compadre a outro, com a marcação do "eu" e do "você", e com a enumeração dos "causos" que rodeiam o aparecimento da máquina na pequena cidade do sertão.

A máquina chega na cidade numa tarde qualquer, sobre "dois ou três caminhões" (2000, p.133), e é montada por homens mal-humorados que "não quiseram dar explicações". Do surgimento da máquina vem, então, o estranhamento. No entanto, devido ao povo da cidade se apaixonar "até pelos assuntos mais infantis" (2000, p.133), o estranhamento vira logo hábito e acomodação, de modo que a máquina passa a ser vista como uma espécie de símbolo da cidade, um diferencial perante os municípios vizinhos, que não têm uma máquina também em sua praça: "Estamos tão habituados com a presença da máquina ali no largo, que se um dia ela desabasse, ou se alguém de outra cidade viesse buscá-la, provando com documentos que tinha direito, eu nem sei o que aconteceria, nem quero pensar" (2000, p.135). Embora não saibam a funcionalidade primordial da máquina, o prefeito designou um funcionário para cuidá-la, além do que, as festividades da cidade passaram a ser comemoradas ao redor do dito objeto.

O narrador ainda delata estranhamento ao especificar o único habitante que não rendeu homenagem à máquina ainda: o vigário. Ter uma posição diferente da do povo em geral, questionar o habitual, é visto como absurdo, uma vez que contradiz o senso comum. A máquina é antropomorfizada, recebe excessiva valorização, enquanto que o tratamento ao humano chega a ser desprestigiado, como se pode notar pela narração do episódio de um rapaz que se machucou na máquina: "um caixeiro da loja do velho Adudes [...] prendeu a perna numa engrenagem da máquina, isso por culpa dele mesmo [...] Também dessa vez a máquina nada sofreu, felizmente" (2000, p.135). Pode-se observar aqui que o advérbio "felizmente" demarca posicionamento positivo quanto ao fato de a máquina manter-se 
inalterada em sua estrutura, enquanto que, ao mencionar o ser humano que perdeu sua perna na máquina, não cabe nenhum advérbio que denote alívio ou felicidade, mas sim uma justificativa negativa ao humano: a culpa é do homem que foi ter com a máquina, de modo algum da máquina que feriu o homem. Uma inversão de valores é proposta pela adoração da tecnologia em detrimento do humano.

Por último, observa-se certa ironia quanto à perspectiva do narrador perante o futuro da máquina. Isenta de utilidade para a população, a máquina produz um aspecto simbólico, talvez de atualização para com a tecnologia desenvolvida em outras partes do país. A presença da máquina é naturalizada, de modo que a descoberta de sua funcionalidade, como aponta o narrador, viria a destituí-la da aura simbólica que a população do lugar a revestira:

Ainda não sabemos para que ela serve, mas isso já não tem maior importância [...] o meu receio é que, quando menos esperarmos, desembarque aqui um moço de fora, desses despachados, que entendem de tudo, olhe a máquina por fora, por dentro, pense um pouco e comece a explicar a finalidade dela [...] se isso acontecer, estará quebrado o encanto e não existirá mais a máquina. (2000, p.135-136)

O absurdo aqui, como no conto anterior, vem do olhar que é lançado à realidade. Se o estranho seria o aparecimento da máquina no local, com o tempo, o estranho passa a ser conviver na cidade sem a presença da máquina, já habitual. Ao mesmo tempo, se o normal seria a busca pela função do "objeto inusitado", essa busca é descrita no conto em sua absurdidade, por ir contra o senso-comum, o habitual, o já convencional. A máquina em si não seria estranha, mas a sua aceitação pelo povo, que desconhece sua função, constitui o absurdo da narrativa, de tal forma que o insólito transforma-se em norma e a natureza resulta absurda.

\section{Considerações finais}

Problemas reais, soluções mágicas; situações estranhas, causas normais. O real e o estranho, assim, na obra de J. J. Veiga, convivem e propiciam ao leitor um novo olhar sobre a realidade. $\mathrm{O}$ abandono da perspectiva infantil, atenta às simples coisas, parece prejudicar uma real busca dos não-limites entre realidade e maravilha. $\mathrm{O}$ espaço rural ou pequeno-urbano, primordial na situação do Brasil, ou ainda, raiz do Brasil, na nomenclatura de Sérgio Buarque de Holanda (1995), é o reino onde a simplicidade esconde seus mistérios. Aliado a isso, temos a invasão da tecnologia e do progresso, aos quais "o homem cordial" brasileiro, forjado pela afetividade, pelo desgosto às relações puramente diplomáticas e polidas, e pelo pensamento 
patriarcal e rural (1995, p.146-147), acomoda-se, aceitando sem entender, na maioria das vezes.

O insólito na obra de J. J. Veiga não consiste na ocorrência de ação ou objeto propriamente estranho, mas sim na total aceitação ou incredulidade que impedem a ponderação. O habitual, sem questionamento, é absurdo porque ignora tudo o que escapa ao senso comum, mesmo que o senso comum não seja o real ou o certo.

\section{Referências}

CHIAMPI, Irlemar. O realismo maravilhoso. Forma e Ideologia no Romance HispanoAmericano. São Paulo: Perspectiva, 1980.

FREUD, Sigmund. O estranho. In. Edição Standard brasileira das obras completas de Sigmund Freud - Volume XVII (1917-1919): Uma neurose infantil e outros trabalhos. Rio de Janeiro: Imago, 1976.

HOLANDA, Sérgio Buarque de. Raízes do Brasil. São Paulo: Companhia das Letras, 2006.

MOISÉS, Massaud. A literatura brasileira através dos textos. São Paulo: Cultrix, 2004.

RODRIGUES, Selma Calasans. O fantástico. São Paulo: Ática, 1988.

SILVERMAN, Malcolm. Moderna ficção brasileira. Rio de Janeiro: Civilização Brasileira; Brasília: INL, 1978.

TODOROV, T. Introdução à Literatura Fantástica. São Paulo: Perspectiva, 1975.

VEIGA, José. J. Melhores contos de J. J Veiga. Seleção de J. Aderaldo Castello. São Paulo: Global, 2000.

WATT, Ian. A ascensão do romance. São Paulo: Cia das Letras, 1999. 


\section{ANEXO I}

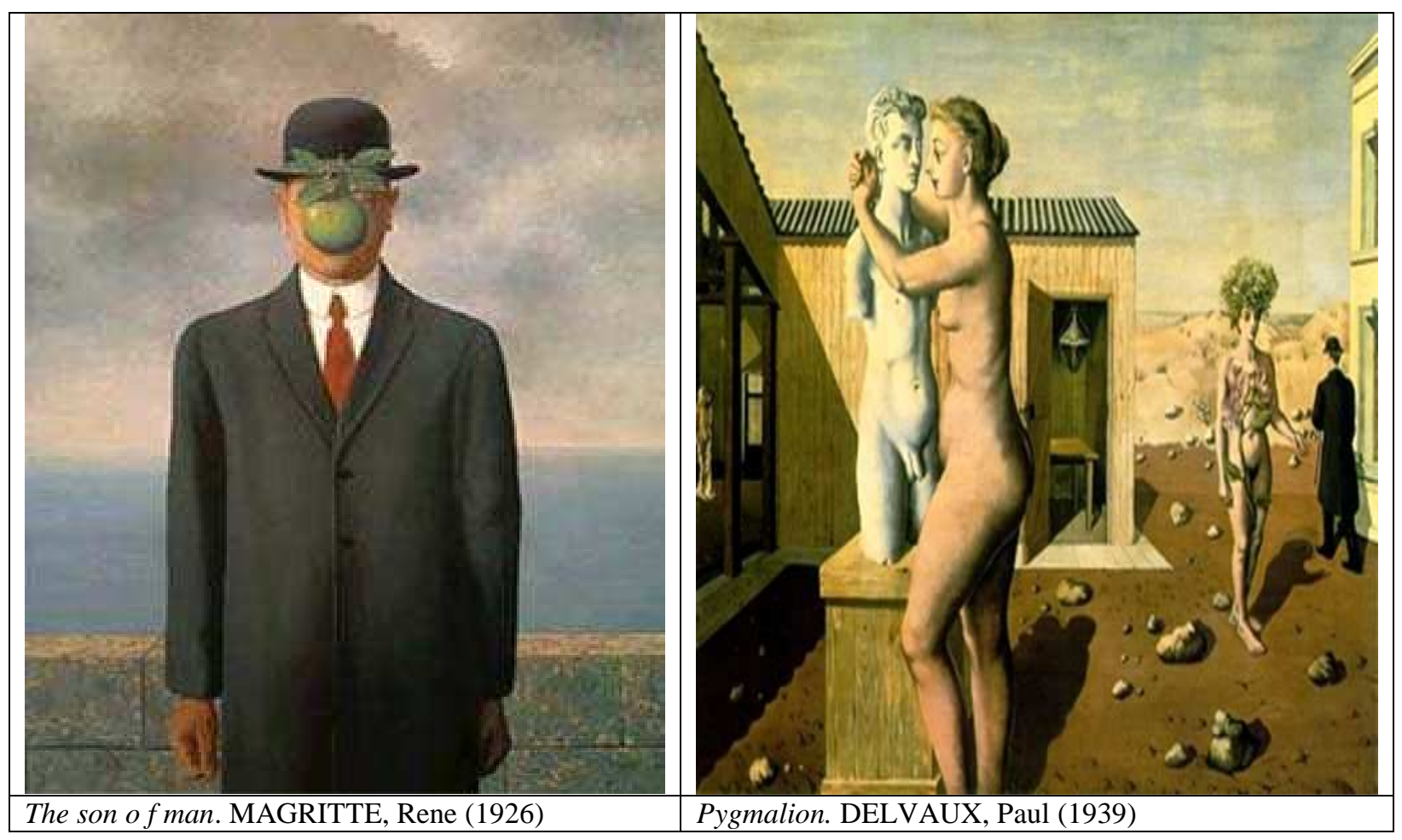

